\title{
Primeira onda folicular e ovulação de vacas primíparas da raça Holandesa alimentadas com diferentes fontes energéticas durante o período de transição
}

[First follicular wave and first postpartum ovulation of primiparous Holstein dairy cows receiving diets with different energetic sources during the transition period]

\author{
M.A.T. Artunduaga1, S.G. Coelho ${ }^{2}$, A.M. Borges ${ }^{2}$, A.M.Q. Lana $^{2}$, R.B. Reis ${ }^{2}$, B.G. Campos $^{3}$, \\ H.M. Saturnino ${ }^{2}$, R.V.Sá Fortes ${ }^{4}$, H.N. Costa ${ }^{3}$ \\ ${ }^{1}$ Facultad de Ciencias Agropecuarias. Universidad de La Salle. Bogotá, Colômbia \\ ${ }^{2}$ Escola de Veterinária - UFMG \\ Caixa Postal 567 \\ 30123-970 - Belo Horizonte, MG. \\ ${ }^{3}$ Aluno de pós-graduação - EV-UFMG - Belo Horizonte, MG \\ ${ }^{4}$ Reagro - Belo Horizonte, MG
}

\begin{abstract}
RESUMO
Avaliou-se o efeito da adição de diferentes fontes energéticas na dieta de vacas leiteiras, durante o período de transição, sobre a primeira onda folicular e o intervalo parto-primeira ovulação. Foram utilizadas 40 vacas primíparas da raça Holandesa, no período de 28 dias antes da data prevista do parto até o $46^{\circ}$ dia pós-parto. As vacas foram submetidas a quatro tratamentos (grupos) durante o período de transição: grupo-controle e grupos tratados com, Megalac-E (sais de cálcio de ácidos graxos da soja), soja tostada ou propileno-glicol. Avaliações ultrassonográficas foram realizadas do $10^{\circ}$ ao $46^{\circ}$ dia pós-parto, com a classificação dos folículos ovarianos em quatro classes (I, II, III e IV) de tamanho e do registro do volume do tecido luteal. Amostras de sangue foram coletadas nos dias 10, 17, 24, 31, 38 e 45 após o parto para análise de progesterona. O padrão de crescimento folicular mais eficiente foi apresentado pelos animais dos grupos Megalac-E e propileno-glicol, que foram caracterizados pela redução no número de folículos de classes I e II e aumento no número de folículos de classes III e IV. Os intervalos entre o parto e a primeira ovulação dos grupos controle, Megalac-E, soja tostada e propileno-glicol foram de 29, 23, 30 e 37 dias, respectivamente $(\mathrm{P}<0,05)$.
\end{abstract}

Palavras-chave: bovino de leite, pré-parto, aditivo gliconeogênico, gordura, pós-parto

\section{ABSTRACT}

The effects of different energy sources added to the diet on the first postpartum ovarian follicle wave and first postpartum ovulation were evaluated. Forty primiparous Holstein dairy cows were used from 28 days before the expected calving date until 46 days postpartum. Cows were randomly allotted to the following groups: control, Megalac-E calcium salts of soybean fatty acid), toasted soybean and propylene glycol. Ovarian structures were scanned using ultrasound from 10 to 46 days postpartum. Follicles were classified according to the diameter in classes I, II, III, and IV and the luteal tissue volume was registered when present. Blood samples for progesterone dosage were colleted on days 10, 17, 24, 31, 38, and 45 post-partum. Follicular growth from groups of salts of polyunsaturated fatty acids and propylene glycol showed to be the most efficient and were characterized by a reduction in the number of classes I and II follicles and an increase in classes III and IV follicles. The first postpartum ovulation after calving for control, salts of polyunsaturated fatty acids, toasted soybean and propylene glycol animal groups occurred at 29, 23, 30, and 37 days, respectively $(P<0.05)$.

Keywords: dairy cow, glyconeogenic additive, fat supplementation, prepartum, postpartum

Recebido em 13 de fevereiro de 2009

Aceito em 28 de dezembro de 2009

*Autor para correspondência (corresponding author)

E-mail: sandra@vet.ufmg.br

Apoio: FAPEMIG (CVZ 600/06) 


\section{INTRODUÇÃO}

A busca pela solução de problemas reprodutivos no pós-parto de vacas leiteiras, reconhecidamente um dos principais fatores influenciando a produtividade do rebanho, não tem avançado de modo consistente em função da abordagem parcial da maioria das pesquisas empreendidas. Muitas vezes aprofunda-se o estudo de características ligadas à nutrição, e em outras à reprodução. Percebe-se hoje, a necessidade de enfrentar o problema por meio de abordagem multidisciplinar, envolvendo aspectos de nutrição e de reprodução e, de acordo com Lucy (2001), poucos são os grupos de pesquisa, em todo o mundo, que se dedicam a esses estudos.

Os efeitos do balanço energético negativo sobre reprodução estão bem estabelecidos (Britt 1992; Zurek et al., 1995), e demonstram a necessidade de formulação de dietas para o período de transição que minimizem a queda na ingestão de matéria seca e a mobilização de reservas corporais no pós-parto (Dann et al., 2006). Todavia, os indicadores de eficiência reprodutiva (intervalo de partos, período de serviço, taxa de concepção etc) continuam demonstrando que, nas fazendas de gado leiteiro, este problema ainda carece de solução.

Grande parte dos estudos que estabeleceram os efeitos do balanço energético negativo sobre a reprodução foi direcionada para investigar os efeitos da dieta sobre o consumo de alimentos, a produção e composição do leite. Menor número preocupou-se em investigar os efeitos da nutrição sobre a reprodução e o perfil metabólico (Staples et al., 1998; Santos et al., 2008). Esses últimos concentraram-se nos efeitos das diferentes fontes de gordura sobre a reprodução, e suas conclusões demonstraram a necessidade de melhor compreensão do efeito da adição de gorduras sobre o desempenho reprodutivo das vacas leiteiras.

Por outro lado, os estudos com aditivos gliconeogênicos têm enfocado seu efeito sobre as doenças metabólicas no pós-parto (Grummer et al., 2004; Butler et al., 2006), mas falta aprofundamento consistente sobre sua utilização em dietas de transição e seus efeitos sobre os parâmetros reprodutivos.

Dessa forma o objetivo deste trabalho foi desenvolver estudo conjunto de aspectos ligados à nutrição e à reprodução, em vacas primíparas que receberam suplementação com fontes de gordura ou fonte gliconeogênica, durante o período de transição.

\section{MATERIAL E MÉTODOS}

Foram utilizadas 40 vacas primíparas da raça Holandesa no período 28 dias antes da data prevista para o parto até o $46^{\circ}$ dia pós-parto. Os animais foram alojados em Free Stall, previamente modificado para que os grupos estivessem completamente isolados uns dos outros, e distribuídos aleatoriamente em quatro grupos experimentais, de acordo com a fonte energética suplementar: os do grupo-controle receberam dieta base no pré e pós-parto; os do grupo Megalac-E ${ }^{\circledR}$ (Arm \& Hammer, QGN), sais de cálcio de ácidos graxos da soja - dieta base suplementada com $100 \mathrm{~g}$ de Megalac-E no pré-parto e $250 \mathrm{~g}$ no pós-parto; os do grupo soja grão tostada - dieta base suplementada com $400 \mathrm{~g}$ de soja tostada no préparto e $800 \mathrm{~g}$ no pós-parto e os do grupo propilenoglicol - dieta base suplementada com $300 \mathrm{~mL}$ de propileno-glicol no pré e pós-parto. As fontes energéticas foram fornecidas uma vez ao dia, misturado a $500 \mathrm{~g}$ de fubá de milho, após individualização dos animais antes da primeira alimentação do dia.

As dietas foram formuladas de acordo com as recomendações do NRC (Nutrient..., 2001), para cada fase do período de transição (Tab. 1 e 2).

O fornecimento das fontes energéticas foi iniciado 28 dias antes da data prevista para o parto, e os tratamentos mantidos até o $21^{\circ}$ dia de lactação, a partir do qual todos os animais passaram a receber alimentação em quantidade suficiente para atender às necessidades nutricionais segundo o NRC (Nutrient..., 2001), até o $46^{\circ}$ dia de lactação. Foram realizados exames ultrassonográficos (Aloka SSD500 , transdutor linear de $5 \mathrm{MHz}$ ) dos ovários, via transretal, sendo as mensurações feitas a partir do $10^{\circ}$ dia após o parto e, repetidas a cada dois dias, até o $46^{\circ}$ dia pós-parto. Foram registrados o número total e os diâmetros máximos $(\mathrm{mm})$ do maior e do segundo maior folículo presentes em cada ovário. Os folículos, classificados de acordo com o diâmetro $(\mathrm{mm})$, foram agrupados em quatro classes: classe I $(3-5 \mathrm{~mm})$, classe II $(6-9 \mathrm{~mm})$, classe III $(10-15 \mathrm{~mm})$ e classe IV $(>15 \mathrm{~mm})$ (Lucy et al., 1991). A primeira ovulação pós-parto foi estabelecida como o primeiro dia em que desapareceu o folículo de maior diâmetro, coincidindo com a formação de corpo lúteo no mesmo local e, assim, foi calculado o intervalo parto-primeira ovulação. A ovulação e a atividade luteal foram confirmadas pela dosagem de progesterona, considerando-se os valores maiores ou iguais a $1 \mathrm{ng} / \mathrm{mL}$ de plasma. 
Tabela 1. Ingredientes e composição nutricional das dietas experimentais usadas no pré-parto de vacas primíparas da raça Holandesa

\begin{tabular}{lcccc}
\hline & Controle & Megalac-E & Soja tostada & Propileno-glicol \\
\hline Ingrediente, kg & & & & \\
Silagem de milho & 24,0 & 24,00 & 24,0 & 24,0 \\
Milho moído & 1,0 & 0,5 & 0,5 & 0,5 \\
Farelo de soja & 1,60 & 1,60 & 1,4 & 1,60 \\
Soja tostada & ----- & ----- & 0,4 & ---- \\
Megalac-E* & ---- & 0,1 & ---- & 300 \\
Propileno-glicol (mL) & - & - & - & 0,4 \\
Premix min-vit pré-parto & 0,4 & 0,4 & 0,4 & \\
Nutrientes, \% da MS & & & & 42,13 \\
Matéria seca (MS) & 42,13 & 42,12 & 42,15 & 42,92 \\
Proteína bruta & 14,63 & 14,77 & 14,97 & 24,61 \\
Fibra em detergente neutro & 41,01 & 42,03 & 42,54 & 3,48 \\
Fibra em detergente ácido & 23,63 & 24,36 & 24,70 & 0,68 \\
Extrato etéreo & 3,48 & 3,50 & 3,47 & 0,43 \\
Ca & 0,68 & 0,68 & 0,68 & 1,52 \\
P & 0,43 & 0,43 & 0,43 & 1,55 \\
Energia liquida lactação (Mcal/kg) & 1,54 & 1,54 & & \\
\hline
\end{tabular}

*Sais de cálcio de ácidos graxos poli-insaturados da soja, composição: extrato etéreo 85\%; ácido linoleico (C18:2): 45\%; ácido linolênico (C18:3): $6 \%$.

${ }^{1}$ Nutron pré-parto 570 CI biotina, composição por kg: Ca: 5\%; P: 1\%; Mg: 1\%; Na: 1\%; Cl: 1,15\%; S: 0,8\%; Co: 39,3ppm; Cu: 660ppm; Fe: 775ppm ; I: 19,5ppm ; Mn: 1630ppm; Se: 8,98 ppm; Zn: 2368 ppm; vitA: 260kIU; vitD: 35kIU; vitE: 2600UI; biotina: 100ppm.

Tabela 2. Ingredientes e composição nutricional das dietas experimentais usadas no pós-parto de vacas primíparas da raça Holandesa

\begin{tabular}{|c|c|c|c|c|}
\hline & Controle & Megalac-E $^{\circledR}$ & Soja tostada & Propileno-glicol \\
\hline \multicolumn{5}{|l|}{ Ingrediente, $\mathrm{kg}$} \\
\hline Silagem de milho & 32,0 & 32,0 & 32,0 & 32,0 \\
\hline Milho moído & 4,5 & 3,5 & 3,5 & 4,5 \\
\hline Farelo de soja & 4,2 & 4,5 & 3,9 & 4,2 \\
\hline Soja tostada & ----- & ---- & 0,8 & ----- \\
\hline Megalac-E ${ }^{\circledR}$ & ----- & 0,25 & ----- & ----- \\
\hline Propileno-glicol (mL) & - & - & - & 300 \\
\hline Bicarbonato de sódio & 0,12 & 0,12 & 0,12 & 0,12 \\
\hline Fosfato bicálcico & 0,12 & 0,12 & 0,12 & 0,12 \\
\hline Calcáreo & 0,14 & 0,14 & 0,14 & 0,14 \\
\hline Óxido de magnésio & 0,04 & 0,04 & 0,04 & 0,04 \\
\hline Premix min-vit pós-parto ${ }^{1}$ & 0,08 & 0,08 & 0,08 & 0,08 \\
\hline \multicolumn{5}{|l|}{ Nutrientes, \% da MS } \\
\hline Matéria seca (MS) & 40,13 & 40,13 & 40,13 & 40,13 \\
\hline Proteína bruta & 16,91 & 17,64 & 17,53 & 16,91 \\
\hline Fibra em detergente neutro & 33,92 & 34,37 & 35,27 & 33,92 \\
\hline Fibra em detergente ácido & 19,23 & 19,67 & 20,22 & 19,23 \\
\hline Extrato etéreo & 3,68 & 3,80 & 3,67 & 3,56 \\
\hline $\mathrm{Ca}$ & 1,10 & 1,10 & 1,10 & 1,10 \\
\hline $\mathrm{P}$ & 0,50 & 0,50 & 0,50 & 0,50 \\
\hline $\begin{array}{l}\text { Energia líquida de lactação } \\
\text { (Mcal } / \mathrm{kg})\end{array}$ & 1,68 & 1,70 & 1,70 & 1,68 \\
\hline
\end{tabular}


As características morfológicas do corpo lúteo foram avaliadas utilizando-se a medição da área da seção transversal $\left(\mathrm{cm}^{2}\right)$, e o volume do tecido luteal $\left(\mathrm{cm}^{3}\right)$ foi calculado pela fórmula matemática modificada de Grygar et al. (1997):

$\mathrm{V}=4 / 3 \pi \cdot \mathrm{a} / 2 \cdot(\mathrm{b} / 2)^{2}$, em que:

$\mathrm{V}=$ volume do tecido luteal $\left(\mathrm{cm}^{3}\right) ; \mathrm{a}=$ eixo longitudinal $(\mathrm{mm})$ e $\mathrm{b}=$ eixo transversal $(\mathrm{mm})$.

Amostras de sangue para a dosagem de progesterona foram coletadas nos dias 10, 17, 24, 31, 38 e 45 pós-parto, e as análises realizadas por radioimunoensaio (RIE) em fase líquida, utilizando-se kits comerciais (Adaltis Progesterona Maia). A sensibilidade e os coeficientes de variação intra e interensaio foram de $0,022 \mathrm{ng} / \mathrm{mL}, 5,7 \%$ e $8,17 \%$, respectivamente.

As análises bromatológicas, das dietas e das sobras, realizadas foram: matéria seca, proteína bruta, fibra insolúvel em detergente neutro (FDN), fibra insolúvel em detergente ácido (FDA), cálcio e fósforo segundo AOAC (Official..., 1980).
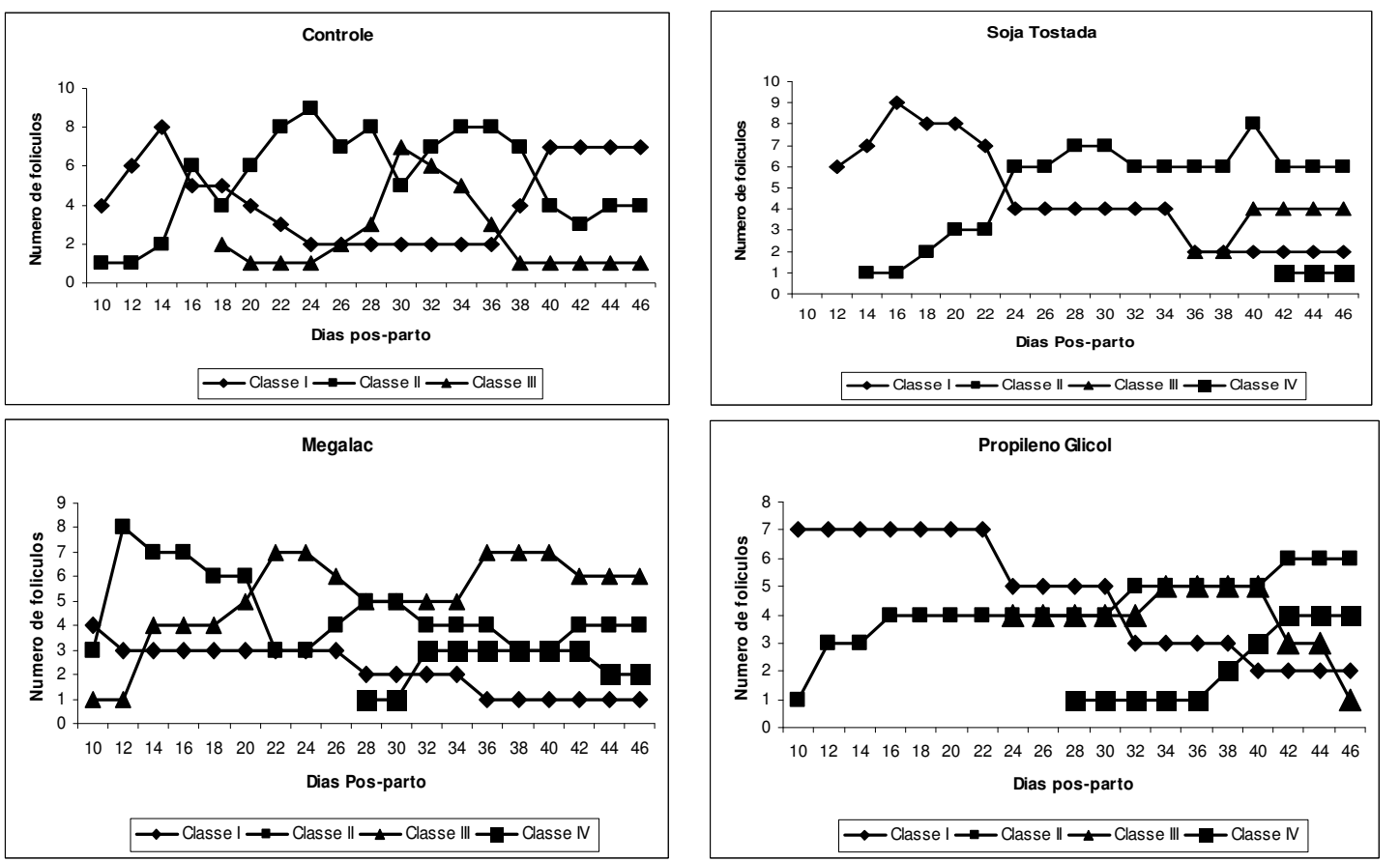

Figura 1. Número de folículos das classes I (3-5mm), II (6-9mm), III (10-15mm) e IV (>15mm), ao longo dos dias pós-parto de vacas primíparas da raça Holandesa, suplementadas com diferentes fontes energéticas na dieta. 
De acordo com a classificação proposta por Lucy et al. (1991), todos os animais apresentaram folículos da classe I $(3-5 \mathrm{~mm})$ do início $\left(10^{\circ} \mathrm{dia}\right)$ ao final da fase experimental ( $46^{\circ}$ dia pós-parto), exceto para os grupos alimentados com MegalacE e propileno-glicol em que ocorreu diminuição na população dos folículos desta classe a partir do dia 26 e 32 após o parto, respectivamente.

O número de folículos de classe II apresentou comportamento similar aos da classe I; para o grupo soja tostada, o aumento do número desses folículos começou quatro dias mais tarde (dia 14 pós-parto), quando comparado com os demais grupos. Na Fig. 1 observa-se que o crescimento dessa classe de folículos substituiu o crescimento de folículos menores (classe I) no grupo Megalac-E ${ }^{\circledR}$.

O aumento na população de folículos da classe III $(10-15 \mathrm{~mm})$, no grupo-controle, iniciou-se aos 18 dias após o parto, sendo maior entre os dias 30 e 38 (Fig. 1), ao contrário do grupo Megalac- $E^{\circledR}$, em que este foi verificado desde o início até o final da fase experimental. Nos outros dois grupos, soja tostada e propilenoglicol, o crescimento começou nos dias 36 e 24, respectivamente.

No grupo-controle não foi observado folículos de classe IV $(>15 \mathrm{~mm})$. No grupo Megalac- $\mathrm{E}^{\circledR}$, observou-se crescimento a partir do dia 28 (Fig. 1), correspondendo a folículos dominantes ovulatórios. No grupo soja tostada, os folículos de classe IV estiveram associados a cistos ovarianos, e no grupo propileno-glicol, alguns desses folículos foram ovulatórios e outros persistentes.

As vacas alimentadas com dietas suplementadas com Megalac-E ${ }^{\circledR}$ e propileno-glicol apresentaram padrão de população folicular caracterizado pela diminuição no número de folículos de classes I e II e aumento no número de folículos maiores (classes III e IV), à medida que aumentaram os dias pós-parto. $\mathrm{O}$ crescimento folicular observado nesses grupos coincide com o conceito de recrutamento, seleção e dominância folicular. De forma geral, os folículos de menor diâmetro (classe I) passam pelos processos de recrutamento e seleção para folículos maiores (6 - 9mm), sendo que esses últimos permanecem em número mais estável provavelmente devido a fato de serem classe folicular transitória onde sempre vão ser encontrados folículos em processos de seleção e dominância.

Não foram observadas diferenças $(\mathrm{P}>0,05)$ no diâmetro do maior folículo e no volume de tecido lúteo entre os animais dos diferentes grupos experimentais (Tab. 3). A utilização de fontes energéticas, em especial o Megalac- $E^{\circledR}$ e $o$ propileno-glicol, anteciparam o crescimento folicular no período pós-parto recente, sem que houvesse modificações no tamanho folicular e no volume do tecido lúteo.

Tabela 3. Média e desvio-padrão do diâmetro do folículo maior (DFM) e do volume do tecido lúteo (VTL), de vacas leiteiras alimentadas com diferentes fontes energéticas durante o período de transição, nos diferentes grupos experimentais

\begin{tabular}{lcc}
\hline \multicolumn{1}{c}{ Grupo } & DFM $(\mathrm{mm})$ & VTL $\left(\mathrm{cm}^{3}\right)$ \\
\hline Controle & $13,95 \pm 2,60$ & $1,78 \pm 0,47$ \\
Megalac-E $^{\circledR}$ & $16,10 \pm 4,90$ & $1,78 \pm 0,95$ \\
Soja tostada & $12,40 \pm 1,64$ & $1,64 \pm 0,73$ \\
Propileno-glicol & $12,70 \pm 3,05$ & $1,16 \pm 0,41$
\end{tabular}

Teste Scott Knott (P>0,05); CV (DFM): 23,8\%; CV (VTL): $42,5 \%$.

A ovulação foi confirmada pela dosagem de progesterona (valores acima de $1 \mathrm{ng} / \mathrm{mL}$ ). Embora o grupo propileno-glicol tenha apresentado padrão caracterizado por folículos das classes III e IV, estes falharam em ovular e se tornaram persistentes (Tab. 4). Assim, o grupo Megalac- $E^{\circledR}$ foi $o$ que apresentou maior percentual de vacas que ovularam, o que coincide com o crescimento folicular precoce relatado anteriormente. Esta observação está de acordo com os resultados observados por Staples et al. (1998), que demostraram maior percentual de vacas ciclando e maior número de corpos lúteos em vacas alimentadas com dietas contendo sais de cálcio de ácidos graxos poli-insaturados.

O grupo Megalac- $\mathrm{E}^{\circledR}$ apresentou o menor intervalo parto-primeira ovulação $(\mathrm{P}<0,05) 23$ dias (Tab. 5), o que se justifica pelo padrão de crescimento folicular observado para este grupo, e favorece a eficiência reprodutiva durante a lactação.

Provavelmente a suplementação das vacas leiteiras com Meglac- $\mathrm{E}^{\circledR}$ foi capaz de minimizar a intensidade das mudanças hormonais e metabólicas, características do período de 
transição e, portanto apresentar redução no intervalo parto - primeira ovulação.

Tabela 4. Número de ovulações segundo análise de progesterona plasmática (P4 acima de $1 \mathrm{ng} / \mathrm{mL}$ ) de vacas leiteiras alimentadas com diferentes fontes energéticas durante o período de transição, nos diferentes grupos experimentais

\begin{tabular}{lcc}
\hline \multirow{2}{*}{ Grupo } & \multicolumn{2}{c}{ Ovulação } \\
\cline { 2 - 3 } & Sim & Não \\
\hline Controle & 6 & 4 \\
Megalac-E $^{\circledR}$ & 7 & 3 \\
Soja tostada & 5 & 5 \\
Propileno glicol & 4 & 6 \\
\hline
\end{tabular}

Teste exato de Fisher $(\mathrm{P}>0,05)$

Tabela 5. Média e desvio-padrão do intervalo parto - primeira ovulação de vacas leiteiras alimentadas com diferentes fontes energéticas durante o período de transição, nos diferentes grupos

\begin{tabular}{lc}
\multicolumn{1}{c}{ Grupo } & Intervalo (dias) \\
\hline Controle & $28,77 \pm 6,47 \mathrm{~b}$ \\
Megalac-E ${ }^{\circledR}$ & $23,30 \pm 6,23 \mathrm{~b}$ \\
Soja tostada & $30,20 \pm 11,32 \mathrm{~b}$ \\
Propileno glicol & $36,75 \pm 4,33 \mathrm{a}$
\end{tabular}

Médias seguidas de letras distintas diferem entre si pelo teste Scott Knott $(\mathrm{P}<0,05)$; CV: 23,5\%.

A melhor resposta folicular observada neste experimento com a adição de Megala- $\mathrm{E}^{\circledR}$ à dieta também foi reportada por alguns autores (Hightshoe et al., 1991; Lucy et al., 1991; Williams, 1996; Lammoglia et al., 1997; De Fries et al., 1998; Staples et al., 1998).

Embora os mecanismos envolvidos na resposta folicular não estejam bem definidos pode-se inferir que os sais de cálcio de ácidos graxos poliinsaturados favorecem o desenvolvimento folicular via metabólitos e hormônios que atuariam no sistema nervoso central influenciando a secreção de GnRH (Lammoglia et al., 1997). Outro mecanismo pelo qual a gordura dietética poderia afetar $\mathrm{o}$ desenvolvimento folicular seria via ação de metabolitos e hormônios diretamente no ovário. Hipoteticamente, os ácidos linoleico (18:2) e linolênico (18:3), têm sido relacionados com o aumento na produção de propionato, o qual poderia ser atribuído à hidrólise de gorduras poliinsaturadas a ácidos graxos de cadeia longa, o que resultou em efeitos insulinogênicos (Williams, 1996). Devido a estes efeitos, a concentração de insulina também estaria aumentada em animais que receberam sais de cálcio de ácidos graxos poliinsaturados (Grummer e Carroll, 1991).

Thomas e Williams (1996) observaram que a suplementação de vacas leiteiras com óleo de soja aumentou a concentração de insulina no plasma, bem como a de IGF-I folicular, o que esteve associado ao melhor padrão de crescimento folicular. A insulina e o IGF-I estimulam a proliferação de células da granulosa in vitro (Adashi et al., 1985; Lammoglia et al., 1997), dessa forma, os sais de cálcio de ácidos graxos poli-insaturados da soja poderiam estar atuando de maneira similar neste experimento, devido ao seu perfil de ácidos graxos (45\% de acido linoleico e $6 \%$ de acido linolênico).

Estes ácidos graxos também poderiam aumentar as concentrações plasmáticas de colesterol, precursor de progesterona, favorecendo a manutenção do corpo lúteo assegurando e ciclos estrais adequados antes da primeira inseminação artificial pós-parto seguido pelo menor intervalo parto - concepção.

Os animais do grupo propileno-glicol apresentaram crescimento folicular precoce, mas o número de vacas que ovularam foi menor que nos demais tratamentos, o que leva a hipotetizar que o propileno-glicol, fornecido durante o período de transição, não foi capaz de aumentar as concentrações de glicose e de insulina, relatadas em outros estudos, e que poderia reduzir o intervalo parto - primeira ovulação (Artunduaga et al., 2008).

Os resultados observados com o uso do propileno-glicol estão de acordo com os de Butler et al.; (2006). Esses autores indicaram que o fornecimento diário de propileno-glicol durante o período de transição, mesmo tendo melhorado o balanço energético, assim como o perfil plasmático de insulina e glicose, não teve impacto positivo na pulsatilidade de LH e na concentração de estradiol, e não se observou melhor padrão de crescimento folicular. As observações anteriores indicam que o aumento 
nas concentrações de insulina e de glicose, bem como a diminuição de ácidos graxos não esterificados, não foram suficientes para estimular, de maneira adequada, o eixo hipotálamo - hipófise - ovariano.

\section{CONCLUSÃO}

A adição de Megalac- $\mathrm{E}^{\circledR}$ (sais de cálcio de ácidos graxos poli-insaturados da soja) durante o período de transição mostrou-se favorável para o retorno à ciclicidade, e pode melhorar o desempenho reprodutivo dos animais.

\section{AGRADECIMENTOS}

Os autores agradecem à FAPEMIG pelo auxílio financeiro para realização deste trabalho, à Fazenda Bom Jardim por ceder às dependências e animais, a Total Alimentos, Cooper Alfa e ARM \& HAMMER. QGN, e a NUTRON.

\section{REFERÊNCIAS BIBLIOGRÁFICAS}

ADASHI, E.Y.; RESNICK, C.E.; D’ERCOLE, A.J. et al. Insulin like growth factors as intraovarian regulators of granulose cell growth and function. Endocr. Rev., v.6, p.400-420, 1985.

ARTUNDUAGA, M.A.T.; SÁ FORTES, R.V.; COELHO, S.G. et al. Atividade ovariana de vacas leiteiras em dietas com propileno-glicol ou monensina no período de transição. Arq. Bras. Med. Vet. Zootec., v.60, p.289-293. 2008.

BRITT, J.H. Reproductive performance as affected by nutrition and environment. In: FLORIDA RUMINANT NUTRITION SYMPOSIUM, 3., 1992, Orlando, Proccedings... Orlando, 1992. p.93-101.

BUTLER, S.T.; PELTON, S.H.; BUTLER, W.R. Energy balance, metabolic status, and the first postpartum ovarian follicle wave in cows administered propylene glycol. J. Dairy Sci., v.89, p.2938-2951, 2006.

DANN, H.M.; LITHERLAND, N.B.; UNDERWOOD, J.P. et al. Diets during far-off and close-up dry periods affect periparturient metabolism and lactation in multiparous cows. $J$. Dairy Sci., v.89, p.3563-3577, 2006.
DE FRIES, C.A.; NEUENDORFF, D.A.; RANDEL, R.D. Fat supplementation influences postpartum reproductive performance in Brahman cows. J. Anim. Sci., v.76, p.864-870, 1998.

GRYGAR, I.; KUDLÁC, E.; DOLEZEF, R.; NEDBÁLKOVÁ, J. Volume of luteal tissue and concentration of serum progesterone in cows bearing homogeneous corpus luteum or corpus luteum cavity. Anim. Reprod. Sci., v.49, p.77-82, 1997.

GRUMMER, R.R.; CARROLL, D.J. Effects of dietary fat on metabolic disorders and reproductive performance of dairy cattle. $J$. Anim. Sci., v.69, p.3838-3852, 1991.

GRUMMER, R.R.; MASHEK, D.G.; HAYIRLI, A. Dry matter intake and energy balance in the transition period. Vet. Clin. N. Am.: Food Anim. Pract., v.20, p.447-470, 2004.

HIGHTSHOE, R.B.; COCHRAN, R.; CORAH, L.R. et al. Effects of calcium soaps of fatty acids on postpartum reproductive function in beef cows. J. Anim. Sci., v.69, p.4097-4103, 1991.

LAMMOGLIA, M.A.S.; WILLARD, S.T.; HALLFORD, D.M. et al. Effects of dietary fat on follicular development and circulating concentrations of lipids, insulin, progesterone, estradiol, PGF $2 \alpha$ and growth hormone in estrous cyclic Brahman cows. J. Anim. Sci., v.75, p.1591-1600, 1997.

LUCY, M.C.; STAPLES, C.R.; MICHEL, F.M. et al. Energy balance and number of ovarian follicles detected by ultrasonography in early post-partum dairy cows. J. Dairy Sci., v.74, p.473-482, 1991.

LUCY, M.C. Reproductive loss in high producing dairy cattle: where it will end? $J$. Dairy Sci., v.84, p.1277-1293, 2001.

NUTRIENT requirements of dairy cattle. 7.ed. Washington: National Academy of Sciences, 2001. 381p

OFFICIAL methods of analisys. 13.ed. Washington: AOAC, 1980. 1015p

SANTOS, J.E.P.; BILBY, T.R.; THATCHER, W.W. et al. Long chain fatty acids as factors influencing reproduction in cattle. Reprod. Dom. Anim., v.43, suppl.2, p.23-30, 2008. 
STAPLES, C.R; BURKE, J.M.; THATCHER, $\mathrm{W} . \mathrm{W}$. Influence of supplemental fats on reproductive tissues and performance of lactating cows. J. Dairy Sci., v.81, p.856-871, 1998

THOMAS, M.G.; WILLIAMS, G.L. Metabolic hormone secretion and FSH-induced superovulatory responses of beef heifers fed dietary fat supplements containing predominantly saturated or polyunsaturated fatty acids. Theriogenology, v.45, p.451-458, 1996.
WILLIAMS, G.L. Influence of dietary fat intake and metabolism on follicular growth in cattle. Reprod. Dom. Anim., v.31, p.539-542, 1996.

ZUREK, E.; FOXCROFT, G.R.; KENELLY, J.J. Metabolic status and interval to first ovulation in post-partum dairy cows. J. Dairy Sci., v.7, p.1909-1920, 1995. 